\title{
Splenorenal venous shunt and normal drainage of splenic vein: an unusual case report
}

\author{
Hadi Sasani $^{1}$, Mehdi Sasani ${ }^{2}$, Arda Kayhan ${ }^{3}$, Mustafa F. Sargon ${ }^{4}$ \\ ${ }^{\prime}$ Department of Radiology, Florence Nightingale Hospital, Istanbul Bilim University, Istanbul, Turkey \\ ${ }^{2}$ Department of Anatomy, Faculty of Medicine, Trakya University, Edirne, Turkey \\ ${ }^{3}$ Medical Imaging Technologies Program Vocational School of Health Services, Esenyurt University, Istanbul, Turkey \\ ${ }^{4}$ Department of Anatomy, Faculty of Medicine, Hacettepe University, Ankara, Turkey
}

\begin{abstract}
The presence of splenorenal shunt without existence of any underlying pathology such as liver cirrhosis, portal hypertension or hepatic encephalopathy, accompanied with normal splenic venous drainage is extremely rare. This case report presents a splenorenal shunt between splenic and left renal vein in a 59-year-old female patient with abdominal pain. No underlying pathology was present. The splenic embryology and contrast enhanced multidetector computed tomography findings of splenorenal shunt have been reported accompanied with a brief review of literature.
\end{abstract}

Keywords: multidetector computed tomography; normal portal circulation; splenorenal venous shunt

Anatomy 2014;8:19-22, (c) 2014 TSACA

\section{Introduction}

Splenorenal venous shunt is a form of extrahepatic portosystemic shunt. Its congenital form usually occurs when the ductus venosus is absent or obstructed as a secondary collateral pathway. ${ }^{[1]}$ Such shunts originate from the splenic vein and drain into the left renal vein. Congenital splenorenal shunts are extremely rare in people without an underlying pathology, primarily portal hypertension. ${ }^{[2]}$ In literature, very few congenital splenorenal shunt cases have been reported. They are frequently large in diameter, multiple and tortuous. Many of these shunts are presented with different symptoms and lead to hepatic encephalopathy. ${ }^{[3,4]}$

In the current case report, an extremely rare congenital splenorenal shunt case with a normal splenic vein drainage incidentally detected in an adult hepatic donor candidate is presented in the light of multidetector computed tomography (MDCT) findings accompanied with a review of literature.

\section{Case Report}

A 59-year-old female patient with the complaint of undefined abdominal pain was admitted to our institution. She was liver donor candidate. A complete physical examination revealed no pertinent findings. Laboratory tests were unremarkable. Abdominal ultrasonography (US) examination and color Doppler US showed no pathology. MDCT examination revealed normal draining portal venous system associated with splenorenal venous shunt (Figure 1). Both the splenic vein (draining from the upper pole of spleen) and the left renal vein calibrations were normal (normal draining splenic vein diameter was $6.7 \mathrm{~mm}$, splenic upper pole draining vein diameter was $7 \mathrm{~mm}$ ) (Figure 2). No cirrhotic appearance of liver and no portal hypertension were found. Ductus venosus was revealed in normal calibration $(0.8 \mathrm{~mm})$ (Figure 3). Additionally, transposition of hepatic flexure and transverse colon was placed in between the diaphragm and liver, consistent with Chilaiditi sign.

\section{Discussion}

Development of the spleen begins at about 4th to 5 th gestational weeks. During this period, vascular anomalies associated with various syndromes may occur. Because the splenic vein and its tributaries are highly variable, any vascular anomalies can occur during the develop- 

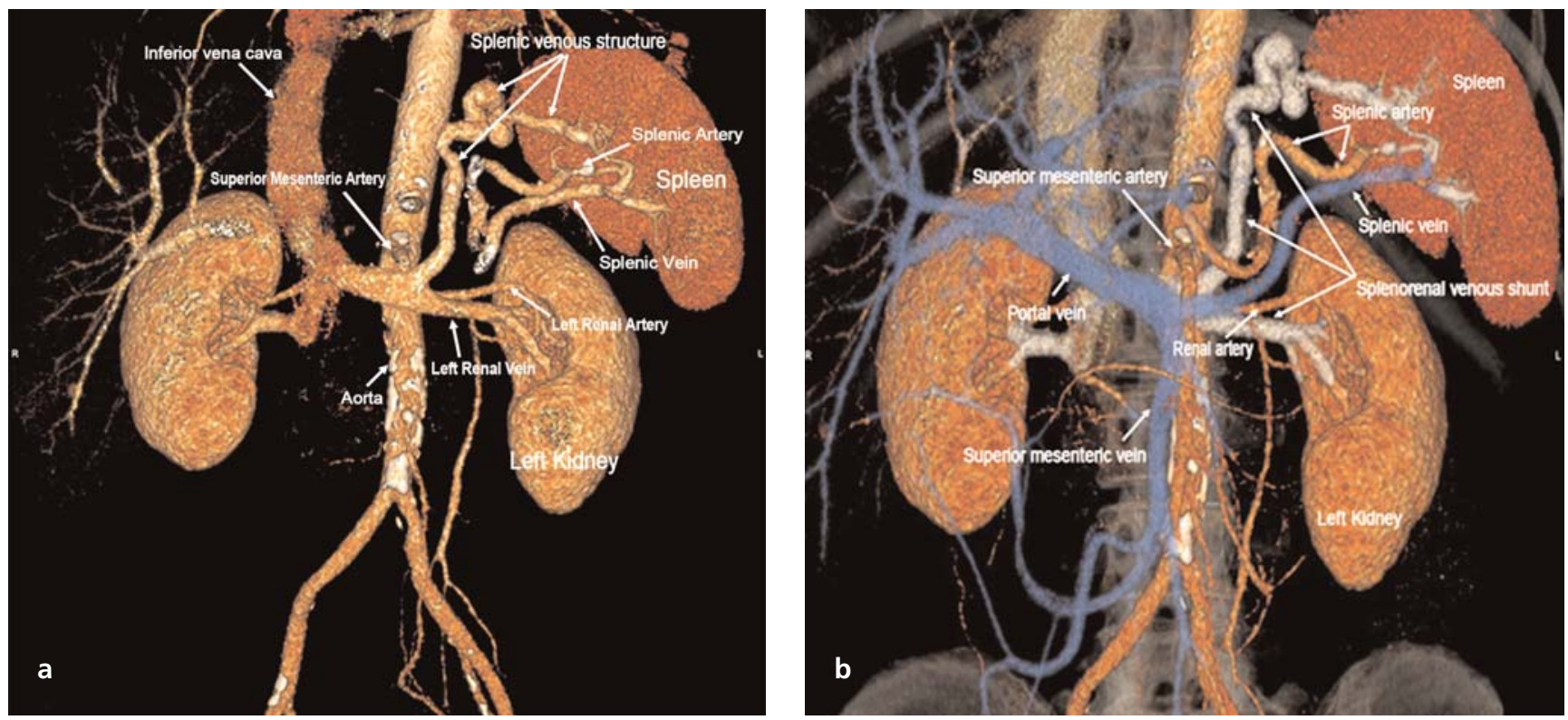

Figure 1. Coronal 3D MDCT images. (a) splenorenal shunt: left renal vein and splenic venous structure (which drains into left renal vein) (b) normal portal venous circulation (blue colored) and splenorenal venous shunt (white colored). [Color figure can be viewed in the online issue, which is available at www.anatomy.org.tr]

mental progression. ${ }^{[5]}$ The initial venous drainage in the embryo is provided by anterior paired cardinal veins draining the cranial portion of the body, and by posterior paired cardinal veins draining the caudal half of the body. The subcardinal veins communicating with hepatic sinusoids provide formation of the hepatic segment of the inferior vena cava (IVC). In the 7th week, the supracardinal veins develop and support the venous drainage of the caudal body. Due to the development of anastomosis of the supracardinal and subcardinal veins, the renal veins are formed as ventral and dorsal veins. Later, the ventral vein becomes the final renal vein, whereas the dorsal vein is gradually degenerated. ${ }^{[6]}$ The primordium of the spleen appears in the 4th and 5th weeks of organogenesis as a mesodermal bulge on the dorsal mesogastrium. ${ }^{[7]}$ A wide range of abnormalities and variations have
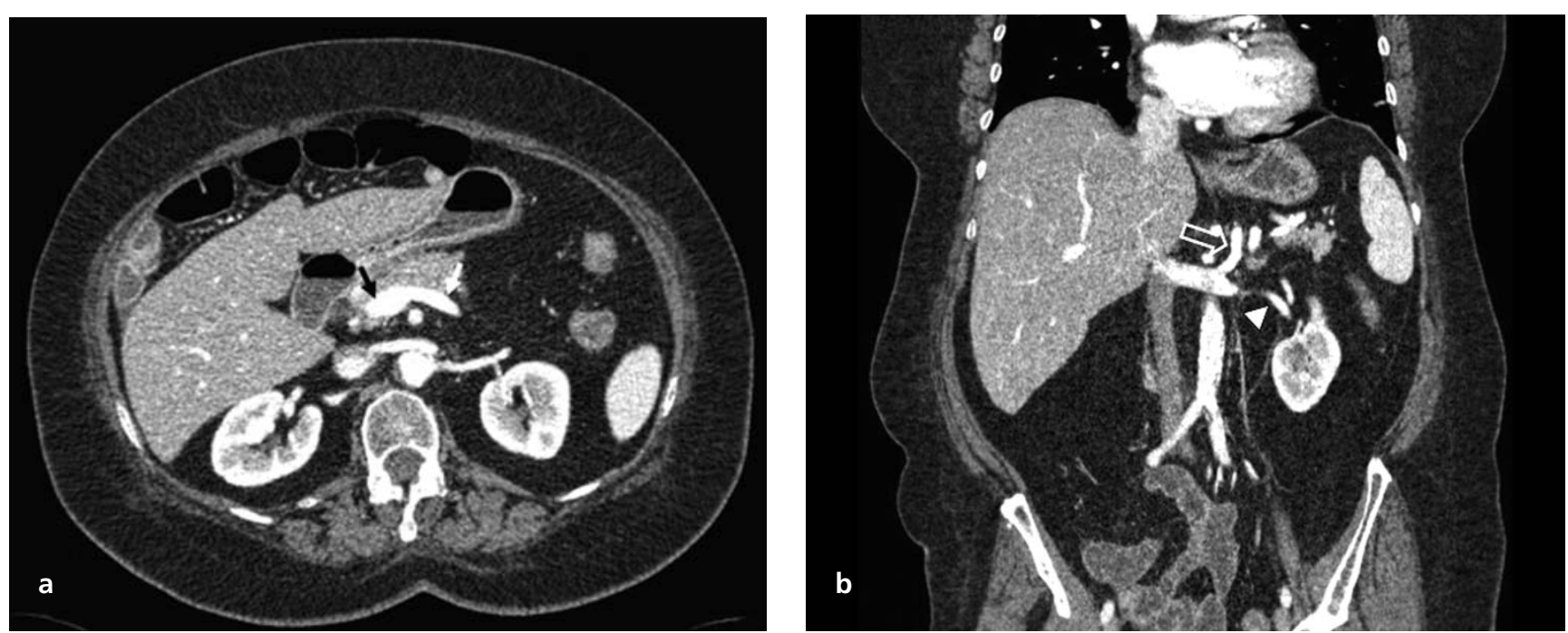

Figure 2. Axial and coronal CT images show the normal draining splenic vein into portal vein (black arrow: splenoportal confluence $12.3 \mathrm{~mm}$; white arrow: splenic vein $6.7 \mathrm{~mm}$ ) (a) and splenic upper pole draining vein (open arrow; $7 \mathrm{~mm}$ ) in normal calibrations. In coronal CT image the left renal vein in normal calibration was shown (arrowhead). 
been previously reported in the literature including splenic anomalies, extrasplenic vessels, ligaments and associated diseases. ${ }^{[8,9]}$

The splenic vein is formed by the combination of five or more veins merging from the hilum. The left gastroepiploic vein and very rarely one or two short gastric veins join to this condensation. The vein then runs through the splenorenal ligament along with the splenic artery. The venous and arterial segmentations of the spleen have unique blood supply for each of independent segment. ${ }^{[9,10]}$

Direct spontaneous splenorenal shunts are rare. These shunts include the development of spontaneous communications between the exorenal circle and the branches of the splenic vein. ${ }^{[11]}$ Splenorenal venous shunt commonly occurs in conditions with underlying diseases including portal hypertension, mesenteric adhesion due to prior surgery, and also abdominal trauma. ${ }^{[12]}$ Splenorenal venous shunt associated with normal portal venous system circulation is a rare condition, as in our case in whom no underlying pathology was present. The laboratory tests were also in normal range.

In literature, there are few cases presenting splenorenal venous shunt without an underlying pathology. Mitra et al. (2012), presented such a shunt between splenic vein and left renal vein in a 2 years old girl. ${ }^{[13]}$ Lin et al (2009) presented a case of an asympomatic spontaneous splenorenal shunt which was detected incidentally by MDCT in a patient with a suspicious adrenal adenoma. ${ }^{[2]}$ It has also been reported that congenital splenorenal venous shunt cases may be asymptomatic in initial followup, however porto-systemic encephalopathy may develop at a later stage. In our case, no such finding was present. The only symptom was abdominal pain which was suggested to be related with Chilaiditi sign. All previously reported cases had diagnosis in either childhood or relatively older ages when they developed signs and symptoms of porto-systemic encephalopathy. In our patient, despite her older age, there was no associated pathology or any sign of systemic symptoms. Ji et al. (1999) reported a case of congenital splenorenal venous shunt detected by prenatal US with the findings of growth retardation, kidney hypoplasia and oligohydramniosis. ${ }^{[9]}$ The researchers proposed that the condition might be related to abnormal circulatory pathway and hemodynamics in the fetus. They stated that, as microscopic examination of the kidneys did not show any findings of congestion, renal hypoplasia was an irrelevant.

In our case, the patient was asymptomatic and the congenital splenorenal venous shunt was detected incidentally by MDCT. The accuracy range of MDCT for detection of renal vascular anomalies is reported to be

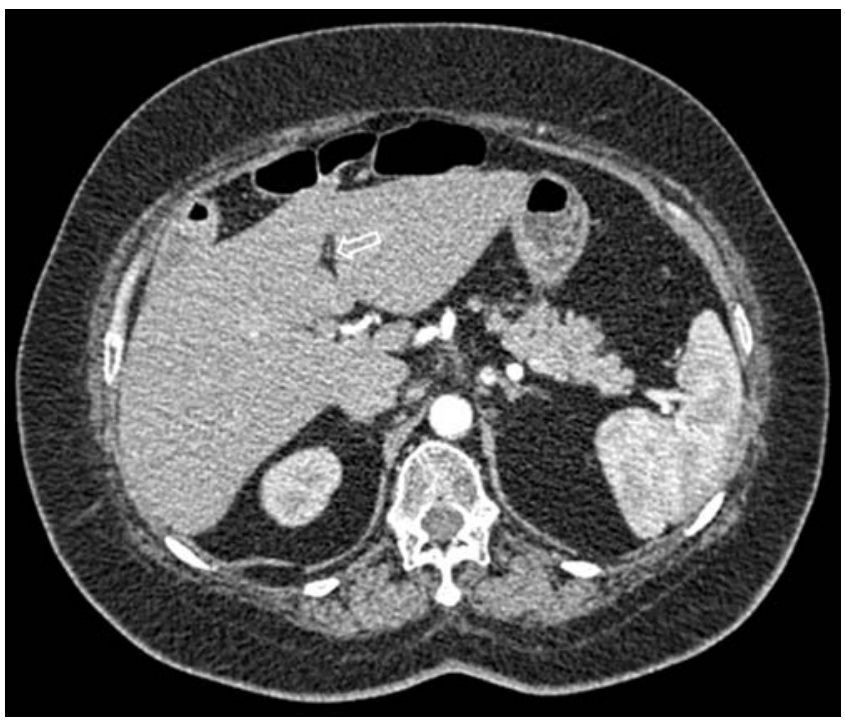

Figure 3. Axial CT image shows ductus venosus in normal calibration (open arrow).

between $96-100 \%$ in the literature. ${ }^{[6]}$ There are several studies stating that MDCT has high sensitivity in the assessment of renal vasculature enabling a reliable quantification of vessel size and evaluation of accessory renal arteries. $^{[14-16]}$ There are other imaging modalities in detection of splenorenal venous shunt including transparietal splenoportography and celio-mesenteric CT angiography, Doppler US and magnetic resonance imaging. ${ }^{[11]}$ However, in our case report the MDCT findings were sufficient to depict the anatomical details.

\section{Conclusion}

The diagnosis of splenorenal venous shunt is crucial due to its clinical and surgical significance. Although the presence of splenorenal venous shunt without underlying pathology is a rare finding, it is essential to be aware of such a condition as it may cause complications due to injury of the shunt vessel.

\section{References}

1. Leonidas JC, Fellows RA. Congenital absence of the ductus venosus: With direct connection between the umbilical vein and the distal inferior vena cava. AJR 1976;126:892.

2. Lin YT, Chang CH, Chen WC. Asymptomatic congenital splenorenal shunt in a noncirrhotic patient with a left adrenal aldosterone-producing adenoma. Kaohsiung J Med Sci 2009;25: 669-74.

3. Ohwada S, Hamada Y, Morishita Y, et al. Hepatic encephalopathy due to congenital splenorenal shunts:report of a case. Surg Today 1994;24:145-9.

4. Kiriyama M, Takashima S, Sahara H, et al. Case report: portal-systemic encephalopathy due to a congenitalextrahepatic portosystemic shunt. J Gastroenterol Hepatol 1996;11:626-9. 
5. Moore KL, Persaud TVN. The digestive system. In: Moore KL, Persaud TVN, eds. The developing human: Clinically orientated embryology. 6th ed. Philadelphia: Saunders; 1998. p. 217-45.

6. He B, Hamdorf JM. Clinical importance of anatomical variations of renal vasculature during laparoscopic donor nephrectomy. OA Anatomy 2013;18:25-31.

7. Lau ST, Kim SS, Lee SL, Ledbetter DJ. The anomalous splenic vein: a case report and review of the literature. J Pediatr Surg 2005;40:1492-4.

8. Kim W, Shin HC, Kim Y, Bae SB, Park JM. Duplication of the spleen with a short pancreas. Br J Radiol 2009;82:42-3.

9. Ji E, Yoo S, Kim JH, Cho KS. Congenital splenorenal venous shunt detected by prenatal ultrasonography. J Ultrasound Med 1999;18:437-9.

10. Huu N, cited by Barnett CH, Lewis OJ. In: Goldby F, Harrison RJ, eds. Recent advances in anatomy, 2nd series. London: J\&A Churchill; 1961. p. 388-92.

11. Wind P, Alves A, Chevallier JM, Gillot C, Sales JP, Sauvanet A, et al. Anatomy of spontaneous splenorenal and gastrorenal venous anastomoses. Review of the literature. Surg Radiol Anat 1998;2: 129-34.

12. Kiriyama M, Takashima S, Sahara H, et al. Porto-systemic encephalopathy due to a congenital extrahepatic portocaval shunt. J Gastroenterol Hepatol 1996;11:626-9.

13. Mitra N, Anandhi C. Congenital splenorenal shunt: a dilemma. Indian Pediatr 2012;49:156-7.

14. Chai JW, Lee W, Yin YH, Jae HJ, Chung JW, Kim HH, et al. CT Angiography for living kidney donors: accuracy, cause of misinterpretation and prevalence of variation. Korean J Radiol 2008;9: 333-9.

15. Villablanca JP, Rodriguez FJ, Stockman T, Dahliwal S, Omura M, Hazany S, et al. MDCT angiography for detection and quantification of small intracranial arteries: comparison with conventional catheter angiography. AJR Am J Roentgenol 2007;188:593602.

16. Satyapal KS, Haffejee AA, Singh B, Ramsaroop L, Robbs JV, Kalideen JM. Additional renal arteries: incidence and morphometry. Surg Radiol Anat 2001;23:33-8.

Correspondence to: Hadi Sasani, MD

Department of Radiology, Florence Nightingale Hospital, Istanbul Bilim University, Istanbul, Turkey

Phone: +90 2122244950 Fax: +90212224 4982

e-mail: hadi.sasani@istanbulbilim.edu.tr

Conflict of interest statement: No conflicts declared. 